\title{
Antinociception induced by stimulating amygdaloid nuclei in rats: changes produced by systemically administered antagonists
}

M.A. Oliveira and W.A. Prado
Departamento de Farmacologia, Faculdade de Medicina de Ribeirão Preto, Universidade de São Paulo, Ribeirão Preto, SP, Brasil
Correspondence

W.A. Prado

Departamento de Farmacologia

FMRP, USP

Av. Bandeirantes, 3900

14049-900 Ribeirão Preto, SP

Brasil

Fax: 55 (016) 633-2301

E-mail: wadprado@fmrp.usp.br

Research supported by FAPESP M.A. Oliveira was the recipient of CAPES and CNPq fellowships

Received July 24, 1997 Accepted February 13, 1998

\section{Abstract}

The antinociceptive effects of stimulating the medial (ME) and central (CE) nuclei of the amygdala in rats were evaluated by the changes in the latency for the tail withdrawal reflex to noxious heating of the skin. A 30-s period of sine-wave stimulation of the ME or CE produced a significant and short increase in the duration of tail flick latency. A 15$\mathrm{s}$ period of stimulation was ineffective. Repeated stimulation of these nuclei at 48-h intervals produced progressively smaller effects. The antinociception evoked from the ME was significantly reduced by the previous systemic administration of naloxone, methysergide, atropine, phenoxybenzamine, and propranolol, but not by mecamylamine, all given at the dose of $1.0 \mathrm{mg} / \mathrm{kg}$. Previous systemic administration of naloxone, atropine, and propranolol, but not methysergide, phenoxybenzamine, or mecamylamine, was effective against the effects of stimulating the CE. We conclude that the antinociceptive effects of stimulating the ME involve at least opioid, serotonergic, adrenergic, and muscarinic cholinergic descending mechanisms. The effects of stimulating the $\mathrm{CE}$ involve at least opioid, $\beta$-adrenergic, and muscarinic cholinergic descending mechanisms.
Key words

- Antinociception

- Amygdala

- Medial nucleus of the amygdala

- Central nucleus of the amygdala

- Tail flick test

- Stimulation-produced antinociception

\section{Introduction}

Behavioral and electrophysiological studies have demonstrated that at many sites in the brain electrical or chemical stimulation produces analgesia by activating centrifugal pathways that act to inhibit sensory neurons in the spinal cord (see Ref. 1). Special attention has been given to the mesencephalic periaqueductal gray (PAG)/dorsal raphe nucleus (DRN) and nucleus raphe magnus (NRM) (see Ref. 2), but evidence exists for the involvement of more rostral structures, including the amygdala, in this central pain control mechanism (see Ref. 3)

The amygdala is a subcortical complex of nuclei considered to be an important site for the induction of morphine analgesia (4), in addition to playing a role in the mediation of emotionality (see Ref. 5). The amygdala also seems to be critical in processing the aspect of noxious stimulation that results in aversive conditioning (6). Most of the information in favor of the involvement of the amygdala in pain control mechanisms derives from experiments on amygdaloid-lesioned animals 
or from the observation that the microinjection of some agonists into the amygdala can evoke antinociception. Lesions of the amygdala, mainly at its basolateral and central (CE) nuclei, attenuate several forms of environmentally induced antinociception (7-10). Bilateral lesions of the $\mathrm{CE}$ abolish the antinociceptive effects of low doses of systemically administered morphine in both the rat tail flick (11) and formalin (12) tests. Microinjection of a K-opioid agonist (13) or neurotensin (14) into the amygdala evokes antinociception. A similar effect was demonstrated in the rat tail flick test following microinjection of carbachol into various amygdaloid nuclei, including the $\mathrm{CE}$ and the medial (ME) nuclei $(15,16)$. Microinjection of morphine into the corticomedial subdivision of the amygdala is effective in the flinch-jump $(17,18)$ and hot plate $(19)$ tests. Microinjection of opioids into the CE $(9,20-25)$ or of serotonin (26) into the basomedial part of the amygdala also induces antinociception.

Few studies, however, have been conducted on the effects of electrical stimulation of the amygdala on nociceptive responses. Early studies have demonstrated that stimulation of the lateral region of the amygdala elicits antinociceptive-like effects while the medial region yields a painful response pattern (27). However, Abbott and Melzack (28) did not obtain immediate antinociception in rats following stimulation of the amygdala. More recently, reduction of visceral pain in cats has been reported to occur after electrical stimulation of the $\mathrm{CE}$ (29). Unilateral stimulation of the basolateral nucleus, CE, or ME did not affect the threshold for the tail withdrawal response evoked by electric shock but increased the tail flick latency (TL) to noxious heat, reduced the tonic phase of the animal response to formalin, and elevated the threshold for vocalization during and after the application of an electric shock to the tail skin (30).

The present study was undertaken to examine the effects of stimulating the $\mathrm{CE}$ or the
ME on the tail flick response evoked by noxious heating of the skin in rats. We demonstrate that a brief $(30 \mathrm{~s})$ stimulus applied to either nucleus evokes antinociception. In addition, we demonstrate that previous systemic administration of methysergide, naloxone, propranolol, phenoxybenzamine or atropine, but not mecamylamine, is effective in inhibiting the antinociception produced by ME stimulation. Moreover, systemic naloxone, atropine and phenoxybenzamine, but not propranolol, methysergide, or mecamylamine, are effective against CE stimulation-produced antinociception.

\section{Material and Methods}

Subjects and surgery

The experiments were conducted on male Wistar rats (140-160 g) housed two to a cage with free access to food and water and maintained at an average ambient temperature of $24^{\circ} \mathrm{C}$ with a 12 -h light-dark cycle before and after surgery. The proposals of the Committee for Research and Ethical Issues of IASP (31) were followed throughout the experiments. Each animal was anesthetized with sodium thiopentone $(50 \mathrm{mg} / \mathrm{kg}$, ip) and a Teflon-insulated monopolar electrode (OD $=0.007$ ") was stereotaxically implanted into the skull to lie in the $\mathrm{CE}$ or ME nuclei. The coordinates used were: $\mathrm{AP}=+5.8, \mathrm{~L}=3.5$, and $\mathrm{H}=-3.2 \mathrm{~mm}$, for the $\mathrm{ME}$, and $\mathrm{AP}=+5.8$, $\mathrm{L}=4.4$, and $\mathrm{H}=-5.5 \mathrm{~mm}$, for the $\mathrm{CE}$, as proposed elsewhere (32). The electrode was then fixed to the skull with two steel screws and dental cement. One of these screws was used as the indifferent electrode. After receiving penicillin $(50 \mathrm{mg} / \mathrm{kg}$, im) the animal was allowed to recover for at least one week before the experiments.

\section{Tail flick test}

The animal was introduced into a ventilated glass tube for a period of up to $20 \mathrm{~s}$, 
with the tail laid across a small wire that was at room temperature $\left(23 \pm 2^{\circ} \mathrm{C}\right)$. The coil temperature was then raised by the passage of electric current, which was previously adjusted to ensure a tail withdrawal reflex within 2.5-3.5 s. A cut-off time of $6 \mathrm{~s}$ was established to minimize the probability of skin damage. Tail flick latencies were measured at 10-min intervals until a stable baseline (BL) was obtained over three consecutive trials. Only rats showing a stable BL after six trials were used in each experiment. Each TL was normalized by an index of antinociception (IA) using the formula IA $=$ (TL - average $\mathrm{BL}) /(6$ - average $\mathrm{BL})$.

Stimulation procedures

Immediately after BL determination the animal was placed inside a glass-walled box $(20 \times 30 \times 35 \mathrm{~cm})$, a $60-\mathrm{Hz}$ sine-wave alternating current was applied to the electrode for 15 or $30 \mathrm{~s}$ and the TL determined within $10 \mathrm{~s}$ and the procedure was repeated at 10min intervals over a period of $30 \mathrm{~min}$. During the stimulation period the drop in voltage across a $1-\mathrm{k} \Omega$ resistor in series with the electrode was continuously monitored on an oscilloscope. No attempt was made to test for the presence of antinociception during the stimulation. Two groups of 5 animals each with electrodes implanted in the ME or $\mathrm{CE}$ were used as sham-stimulated rats.

A group of 18 rats with electrodes implanted in the ME or CE was preliminarily used for the determination of the $\mathrm{CI}_{50}$, i.e., the current intensity producing an antinociceptive effect in $50 \%$ of the animals in the experimental group. For calculation, antinociception was arbitrarily considered to occur whenever IA $\geq 0.5$ was obtained. Immediately after BL determination each animal received $30 \mathrm{~s}$ of brain stimulation, and the TL was determined up to $10 \mathrm{~s}$ later. During this first stimulation period the lowest current of $1.4 \mu \mathrm{A}$ root mean square (rms) was used and then increased to $3.5 \mu \mathrm{A}$ in a sec- ond test $5 \mathrm{~min}$ later and to a maximum of 35 $\mu \mathrm{A}$ in a stepped sequence of $1.4,3.5,7.0$, $10.0,14.0,21.0,35.0 \mu \mathrm{A}$ rms. The animals were spared further stimulation whenever IA $=1.0$ was obtained.

Histology

At the end of the experiment the animal was killed with an overdose of sodium thiopentone and perfused through the heart with formalin. Electrode tracks were localized on $50-\mu \mathrm{m}$ serial coronal sections stained with neutral red, and identified on diagrams from the atlas of König and Klippel (32).

Statistical analysis

The $\mathrm{CI}_{50}$ was calculated by the method of Litchfield and Wilcoxon (33). The results of the remaining studies are reported as graphs of averaged IA ( \pm SEM) values against time of reading for a group of rats. The effects of different treatments on IA were analyzed statistically by multivariate analysis of variance (MANOVA) with repeated measures to compare the groups over all times. The factors analyzed in the experiments of ME or $\mathrm{CE}$ stimulation were treatments, time and treatment $x$ time interaction. In the case of significant treatment $\mathrm{x}$ time interactions a one-way ANOVA followed by the Duncan test was performed for each time. The analysis was performed using the statistical software package SPSS/PC+, version 3.0, and the level of significance was set at $\mathrm{P}<0.05$.

Drugs

A range of antagonists were administered intraperitoneally. Naloxone hydrochloride and phenoxybenzamine hydrochloride were from RBI (Research Biochemicals International, Natick, MA), atropine sulfate, mecamylamine hydrochloride, and propranolol hydrochloride were from Sigma Chemical Co. (Saint Louis, MO), and methysergide 
bimaleate was from Sandoz (Basel, Switzerland). The antagonists were all dissolved in saline and given at the dose of $1.0 \mathrm{mg} / \mathrm{kg}, 10$ $\min$ (naloxone, atropine, and propranolol), 15 min (methysergide and mecamylamine), or $3 \mathrm{~h}$ (phenoxybenzamine) before intracerebral stimulation. A longer interval had to be
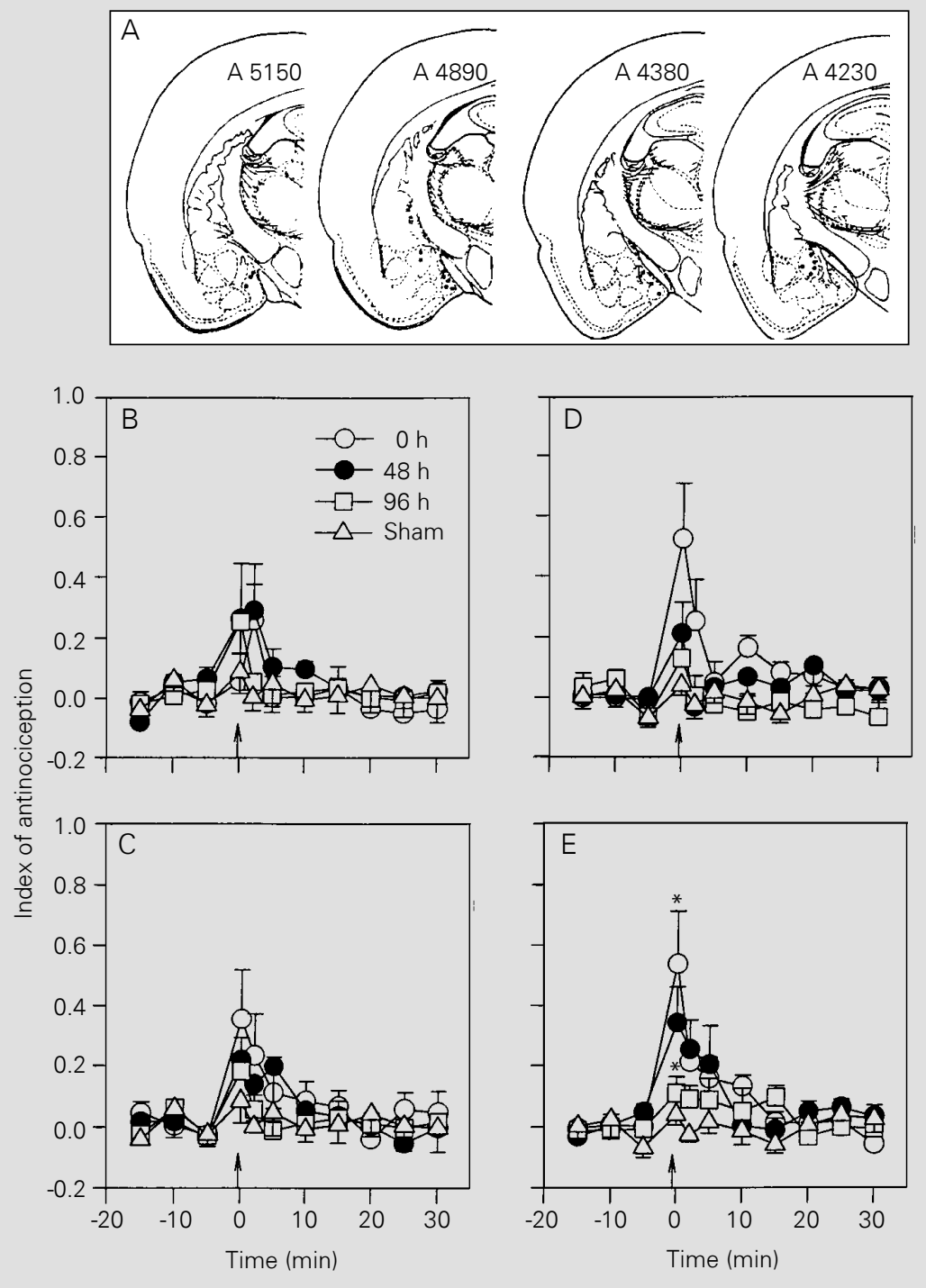

Figure 1 - Antinociceptive effects of stimulating the medial or central nuclei of the amygdala. (A) Cross sections taken from the atlas of König and Klippel (32), at the indicated AP levels, showing the location of the sites stimulated during experiments for the determination of current thresholds. The remaining graphs show the time-course of the effects of stimulating the medial ( $B$ and $D$ ) or the central ( $C$ and $E$ ) nuclei of the amygdala for 15 or $30 \mathrm{~s}$, respectively, on three different occasions at $48-h$ intervals. $N=4$ for the curves of graph $\mathrm{C}$ and 5 for the remaining graphs. ${ }^{*} P<0.05$ compared to sham-stimulated animals (Duncan test). used between phenoxybenzamine administration and brain stimulation because the central effects of this drug develop slowly (34).

\section{Results}

Determination of the current intensity applied to the ME and CE for the production of antinociception

The latency for the tail flick reflex was increased by electrical stimulation of ME or $\mathrm{CE}$ at the sites depicted in Figure 1A. The current intensity for the maximal possible effect in the test $(\mathrm{IA}=1.0)$, however, varied widely. One of eleven animals stimulated in the ME with a current intensity of $1.4 \mu \mathrm{A}$ rms yielded $\mathrm{IA}=1.0$, whereas other rats showed full antinociception after stimulation with current intensities of 3.5 (2 animals), and 7.0, 10.0, 14.0, and $21.0 \mu \mathrm{A} \mathrm{rms}$ ( 1 animal at each intensity). Four animals did not show a full effect even after stimulation at $35 \mu \mathrm{A}$ rms. Similar results were obtained for 7 rats stimulated in the CE. Full antinociception was obtained at current intensities of 1.4 and $10.0 \mu \mathrm{A}$ rms ( 2 animals each) and at 3.5 and $7.0 \mu \mathrm{A} \mathrm{rms} \mathrm{(1} \mathrm{animal}$ each). The remaining animal did not show a full effect even at the current intensity of $35.0 \mu \mathrm{A}$. The $\mathrm{CI}_{50}$ were 10.11 (confidence limits $=7.99$ and 11.87) and 5.16 (3.74 and 6.29) $\mu \mathrm{A}$ rms for the ME and CE, respectively. We therefore decided to stimulate systematically these nuclei with $21.0 \mu \mathrm{A}$ rms.

Time-course of the effects of stimulating the ME and CE. Influence of duration of the stimulation and repeated stimulation

Stimulation of the ME (Figure 1B) or CE (Figure 1C) with $21.0 \mu \mathrm{A}$ over a period of 15 s produced a slight increase in the index of antinociception (26\% and $35 \%$ for ME and CE stimulation, respectively) and the effects 
did not change significantly for experiments repeated 48 or $96 \mathrm{~h}$ later. The effects were stronger and of short duration following stimulation of the ME (Figure 1D) or CE (Figure $1 \mathrm{E})$ with the same current intensity applied over a period of $30 \mathrm{~s}$ ( $58 \%$ and $54 \%$ for $\mathrm{ME}$ and $\mathrm{CE}$ stimulation, respectively), but the effects were smaller when the stimulation was repeated 48 and $96 \mathrm{~h}$ later. The curves in Figure $1 \mathrm{~B}$ and $\mathrm{C}$ did not differ significantly regarding the different occasions of stimulation $\left(\mathrm{F}_{3,16}=0.97, \mathrm{P}=0.43\right.$, and $\mathrm{F}_{3,16}=1.15$, $\mathrm{P}=0.36$, respectively) nor did they show significant effect $\mathrm{x}$ time interactions $\left(\mathrm{F}_{21,112}\right.$ $=0.96, \mathrm{P}=0.52$, and $\mathrm{F}_{21,112}=1.01, \mathrm{P}=0.46$, respectively). The curves in Figure 1D did not differ when the different occasions of stimulation were compared $\left(\mathrm{F}_{3,13}=1.73, \mathrm{P}=\right.$ 0.21 ) and showed no significant effect $x$ time interaction $\left(\mathrm{F}_{21,91}=1.10, \mathrm{P}=0.35\right)$. The curves in Figure 1E were significantly different $\left(\mathrm{F}_{3,16}=3.89, \mathrm{P}=0.029\right)$ and showed a significant effect $\mathrm{x}$ time interaction $\left(\mathrm{F}_{21,112}=\right.$ $2.42, \mathrm{P}=0.002)$. The effects obtained for animals stimulated in the $\mathrm{CE}$ on the first occasion were significantly different from those obtained for sham-stimulated rats at times 0 and $2 \min$ (ANOVA followed by the Duncan test). The subsequent experiments were then conducted on animals stimulated only once with a current intensity of $21.0 \mu \mathrm{A}$ rms applied to each nucleus over a period of $30 \mathrm{~s}$.

Some rats stimulated in the $\mathrm{CE}$ presented aversive-like behaviors during stimulation, including vocalization, masticatory movements and attempts to escape from the box. Apparently, the frequency of behaviors evoked by stimulating these nuclei was not changed by increasing the duration of the stimulation. Escape was also observed in some rats stimulated in the ME. These behaviors were more frequent during longer periods of stimulation. After the end of stimulation, no gross motor disturbance was detected. The animals walked and responded normally to innocuous stimuli. No attempt was made to quantify these behaviors in the present study.

Effects of ip administration of antagonists on the antinociception induced by stimulation of the ME

Six groups of rats were treated by ip administration of antagonists, $10 \mathrm{~min}$ (naloxone, atropine, and propranolol), $15 \mathrm{~min}$ (methysergide and mecamylamine) or $3 \mathrm{~h}$ (phenoxybenzamine) before intracerebral stimulation. All drugs were given at the dose of $1 \mathrm{mg} / \mathrm{kg}$. A group of rats treated with saline $(0.1 \mathrm{ml} / \mathrm{kg}$, ip) was used as control.

Naloxone (Figure 2A), methysergide (Figure 2B), phenoxybenzamine (Figure 2C), atropine (Figure 2D) and propranolol (Figure $2 \mathrm{E}$ ), but not mecamylamine (Figure $2 \mathrm{~F}$ ), significantly inhibited the antinociceptive effects of stimulating the ME. The curves in Figure 2 did not differ significantly regarding treatments $\left(\mathrm{F}_{6,39}=2.33, \mathrm{P}=0.05\right)$ but showed a significant treatment $\mathrm{x}$ time interaction $\left(\mathrm{F}_{42,273}=2.44, \mathrm{P}<0.001\right)$. On the other hand, naloxone (Figure 3A), atropine (Figure 3B), and propranolol (Figure 3C), but not methysergide (Figure 3D), mecamylamine (Figure 3E), or phenoxybenzamine (Figure $3 \mathrm{~F}$ ), were effective against the antinociception induced by stimulation of the CE. The curves in Figure 3 differed significantly regarding treatments $\left(\mathrm{F}_{6,38}=5.10, \mathrm{P}=0.001\right)$ and showed a significant treatment $\mathrm{x}$ time interaction $\left(\mathrm{F}_{42,266}=2.31, \mathrm{P}<0.001\right)$. The antagonists alone had no significant effect on tail flick latency.

\section{Discussion}

The present study demonstrated that stimulation of the $\mathrm{ME}$ or $\mathrm{CE}$ in rats produced antinociception in the tail flick test. Behavioral changes such as vocalization, masticatory movements and attempts to escape from the restraining box were occasionally observed during the stimulation period. Masti- 
catory movements during stimulation of the $\mathrm{CE}$ have also been reported elsewhere (35).

The antinociceptive effects of stimulating the ME or the $\mathrm{CE}$ were dependent on the pattern of electrical stimulation. The current intensity required for a full antinociceptive effect was variable, the $\mathrm{CE}$ being more sen-

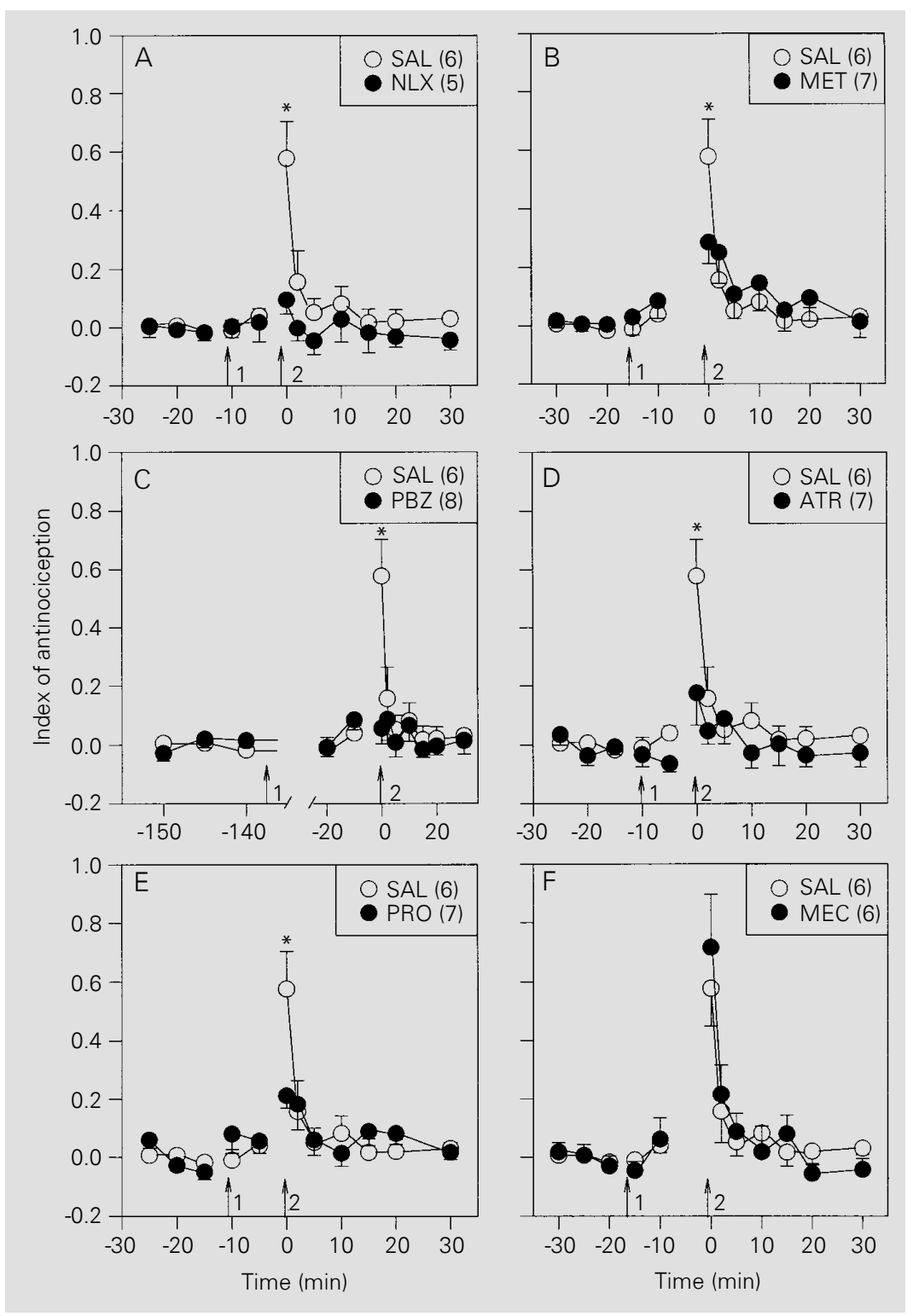

Figure 2 - Effects of intraperitoneal administration (arrow 1) of saline (SAL; $0.1 \mathrm{ml} / \mathrm{kg}$ ) or antagonists $(1 \mathrm{mg} / \mathrm{kg}$ ) on the antinociception induced by electrical stimulation (arrow 2) of the medial nucleus of the amygdala of rats. A, Effect of naloxone (NLX); $B$, effect of methysergide (MET); $C$, effect of phenoxybenzamine (PBZ); $D$, effect of atropine (ATR); $E$, effect of propranolol (PRO); $F$, effect of mecamylamine (MEC). The number of rats per curve is given in parentheses. Data are reported as mean \pm SEM for each group of rats. ${ }^{*} \mathrm{P}<0.05$ compared to drug-treated animals (Duncan test). sitive than the ME. Electrical stimulation of these nuclei was more effective when applied for $30 \mathrm{~s}$ than when applied for $15 \mathrm{~s}$. The small monopolar electrodes used in these experiments reduce the risk of tissue lesion and the occurrence of edema at the site reached by the electrode tip. Moreover, the biphasic alternating current applied to monopolar electrodes allows a more focal stimulation of the target structure (36).

We have also shown that the antinociception evoked from the ME or CE was progressively weaker when the stimulation was repeated at 48 -h intervals. The repeated stimulation of the amygdala may somehow cause irreversible or long-lasting functional changes at the site of stimulation. Repeated stimulation of the amygdala may produce kindling, a phenomenon that may change the animal's responsiveness to pain (37). An alternative explanation for the phenomenon could be the development of tolerance to the stimulation. Similar changes induced by repeated stimulation of the PAG have been previously demonstrated, and probably involve the participation of endogenous opioid modulation (38). In fact, opioid mechanisms may participate in the antinociception evoked by amygdaloid stimulation. The $\mathrm{ME}$ and $\mathrm{CE}$ express mRNA for $\mu$ - and $\kappa$-opioid receptors $(39,40)$. Fibers and terminals immunoreactive to $B$-endorphins (41) or enkephalins $(42,43)$ were demonstrated in the ME and $\mathrm{CE}$, respectively. Our data, however, do not allow us to conclude about the mechanism involved in the reduced effectiveness of repeated stimulation of the ME or CE.

The antinociceptive effects of stimulating the ME were significantly inhibited by the previous systemic administration of naloxone (an opioid receptor antagonist), methysergide (a 5-HT receptor antagonist), atropine (a muscarinic cholinergic receptor antagonist), phenoxybenzamine (an $\alpha$ adrenoceptor antagonist), and propranolol (a ß-adrenoceptor antagonist), but not by mecamylamine (a nicotinic cholinergic re- 
ceptor antagonist). Naloxone, atropine, and propranolol, but not methysergide, phenoxybenzamine, or mecamylamine, were significantly effective against the antinociception induced by stimulating the CE. These antagonists were all used at doses already known to be effective against similar effects induced by the stimulation of other brain structures known to participate in the descending control of pain (44-48). The effectiveness of propranolol against the stimulation-produced antinociception from the ME or CE is indicative that $B$-adrenergic mechanisms may be involved in the phenomenon. Propranolol exhibits local anesthetic properties and has affinity also for a range of serotonergic receptor subtypes (49). A local anesthetic effect of propranolol seems to depend on higher drug concentrations (see 50) and is, therefore, unlikely to be the reason for its inhibitory effect found in this study. The present results do not allow us to exclude that the effectiveness of propranolol against the stimulation-produced antinociception from the ME derives from its 5-HT antagonist property. However, the nonspecific 5-HT antagonist methysergide was effective against the effect of stimulating the ME, but not the CE. Thus, B-adrenergic mechanisms may also be involved in the descending mechanism activated from the CE. The different profiles of effectiveness of the antagonists used in this study provide evidence that the $\mathrm{ME}$ and CE function separately to produce inhibition of the tail flick reflex.

The tail flick escape from noxious heat is a spinal reflex (51) and its inhibition by stimulating supraspinal structures indicates that this action may somehow inhibit spinal mechanisms. Motor impairment produced by intracerebral stimulation could be one reason for the inhibition of the tail flick reflex. Objective tests for motor changes were not conducted in the present study. However, no gross motor disturbance was detected throughout the experiments. The animals walked normally after the stimula- tion period and responded to innocuous stimuli.

Few reports are available regarding direct projections from the amygdala to the spinal cord. A sparse population of CE neurons in monkeys (52) and cats (53) projects
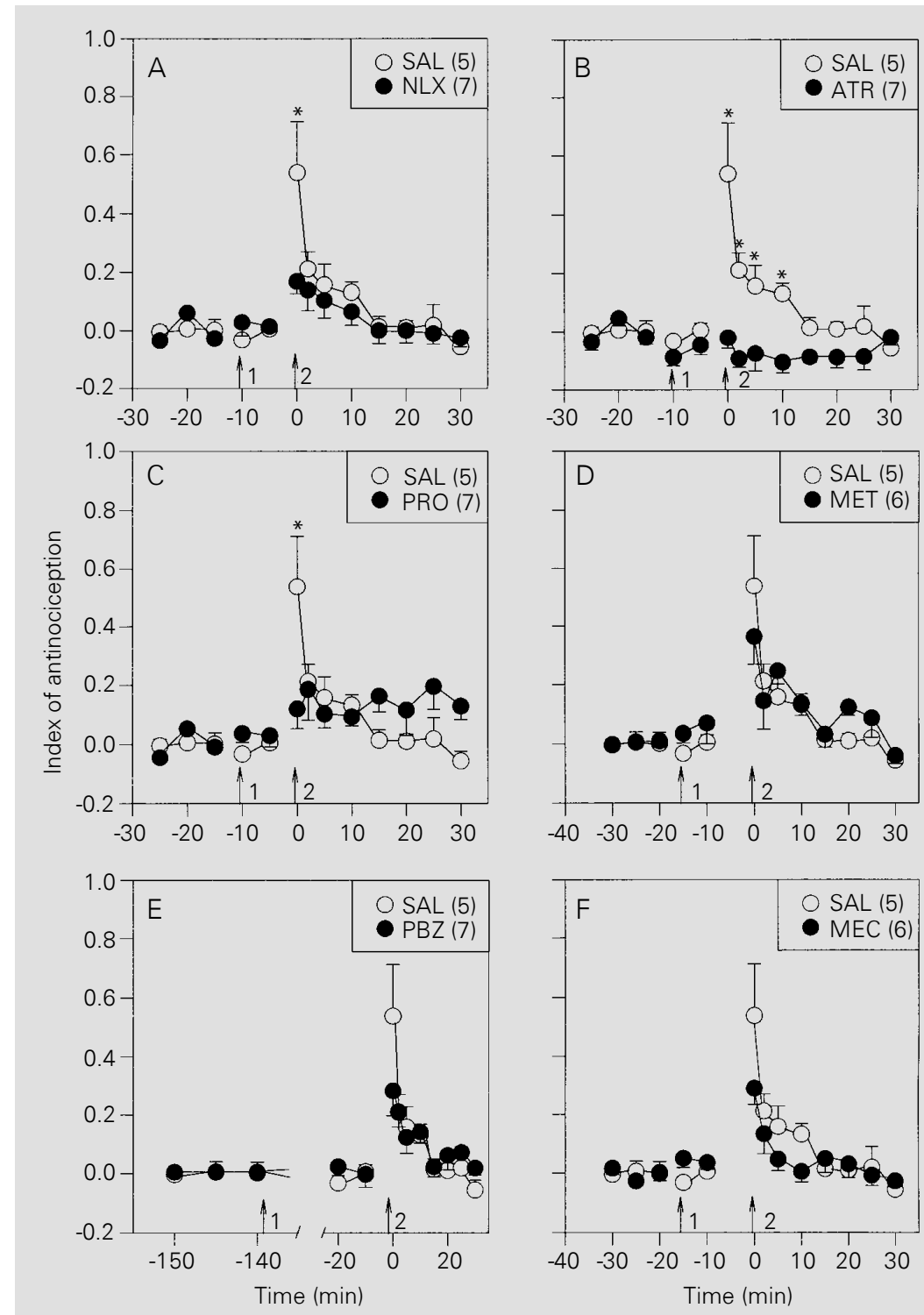

Figure 3 - Effects of intraperitoneal administration (arrow 1) of saline (SAL; $0.1 \mathrm{ml} / \mathrm{kg}$ ) or antagonists (1 $\mathrm{mg} / \mathrm{kg}$ ) on the antinociception induced by electrical stimulation (arrow 2) of the central nucleus of the amygdala of rats. $A$, Effect of naloxone (NLX); $B$, effect of atropine (ATR); $C$, effect of propranolol (PRO); $D$, effect of methysergide (MET); $E$, effect of phenoxybenzamine (PBZ); $F$, effect of mecamylamine (MEC). The number of rats per curve is given in parentheses. Data are reported as means \pm SEM for each group of rats. ${ }^{*} \mathrm{P}<0.05$ compared to drug-treated animals (Duncan test). 
to the cervical spinal cord. Alternatively, anatomical studies have demonstrated direct reciprocal projections between the amygdala and the PAG (54-59). The CE $(56,60)$ and $\mathrm{ME}(55,56,61)$ have direct and indirect (via the hypothalamus) connections with the PAG. The CE also sends projections to the parabrachial nucleus $(62,63)$ and locus coeruleus $(60,64)$, which are structures also known to exert antinociceptive effects when electrically stimulated $(65,66)$. Thus, the depression of the tail flick reflex by stimulating the ME or CE probably involves activation of descending pathways that utilize relay stations before reaching the spinal cord.
In summary, this study demonstrates that brief electrical stimulation of the $\mathrm{ME}$ and $\mathrm{CE}$ amygdaloid nuclei increases the tail flick response latency. The effect obtained from the ME involves at least opioid, serotonergic, adrenergic, and muscarinic cholinergic mechanisms. The effect from the $\mathrm{CE}$ seems to depend on at least opioid, $B$-adrenergic, and muscarinic cholinergic mechanisms.

\section{Acknowledgments}

We thank P.R. Castania for technical support.

\section{References}

1. Basbaum Al (1982). Anatomical substrates for the descending control of nociception. In: Sjölund B \& Björklund A (Editors), Brain Stem Control of Spinal Mechanisms. Elsevier, Amsterdam, 119-133.

2. Besson JM \& Chaouch A (1987). Peripheral and spinal mechanisms of nociception. Pharmacological Reviews, 67: 67186.

3. Kuypers HGJM (1982). A new look at the organization of the motor system. In: Kuypers HGJM \& Martin GF (Editors), Anatomy of Descending Pathways to the Spinal Cord. Progress in Brain Research. Vol. 57. Elsevier, Amsterdam, 381-403.

4. Zhou ZF, Du MY, Jiang Y \& Han JS (1981). Effect of intracerebral microinjection of naloxone on acupuncture and morphine analgesia in the rabbit. Scientia Sinica, 24: 1166-1178.

5. LeDoux JE (1987). Emotion. In: Plum F (Editor), Handbook of Physiology: Nervous System V. American Physiological Society, Washington, DC, 419-459.

6. Good AJ \& Westbrook RF (1995). Effects of a microinjection of morphine into the amygdala on the acquisition and expression of conditioned fear and hypoalgesia in rats. Behavioral Neuroscience, 109: 631-641.

7. Helmstetter $F$ (1992). The amygdala is essential for the expression of conditioned hypoalgesia. Behavioral Neuroscience, 106: 518-528.

8. Helmstetter F \& Bellgowan PS (1993).
Lesions of the amygdala block conditional hypoalgesia in the tail flick test. Brain Research, 612: 253-257.

9. Watkins LR, Wiertelak EP \& Maier SF (1993). The amygdala is necessary for the expression of conditioned but not unconditioned analgesia. Behavioral Neuroscience, 107: 402-405.

10. Fox RJ \& Sorenson CA (1994). Bilateral lesions of the amygdala attenuate analgesia induced by diverse environmental challenges. Brain Research, 648: 215-221.

11. Manning BH \& Mayer DJ (1995). The central nucleus of the amygdala contributes to the production of morphine antinociception in the rat tail-flick test. Journal of Neuroscience, 15: 8199-8213.

12. Manning BH \& Mayer DJ (1995). The central nucleus of the amygdala contributes to the production of morphine antinociception in the formalin test. Pain, 63: 141152.

13. Helmstetter FA, Brozoski EL \& Frost JÁ (1991). Kappa opioid agonists produce hypoalgesia in the tail flick test after application to the amygdala. Society for Neuroscience Abstracts, 17: 296.

14. Kalivas PW, Gau BA, Nemeroff CB \& Prange AJ (1982). Antinociception after microinjection of neurotensin into the central amygdaloid nucleus of the rat. Brain Research, 243: 279-286.

15. Klamt JG \& Prado WA (1991). Antinociception and behavioral changes induced by carbachol microinjected into identified sites of the rat brain. Brain Research, 549: 9-18.

16. Oliveira MA \& Prado WA (1994). Antinociception and behavioral manifestations induced by intracerebroventricular or intraamygdaloid administration of cholinergic agonists in the rat. Pain, 57: 383-391.

17. Rodgers RJ (1977). Elevation of aversive threshold in rats by intra-amygdaloid injection of morphine sulfate. Pharmacology, Biochemistry and Behavior, 6: 385390.

18. Rodgers RJ (1978). Influence of intraamygdaloid opiate injections on shock thresholds, tail flick latencies and open field behavior in rats. Brain Research, 153: 211-216.

19. Yaksh TL, Al-Rodhan NRF \& Jensen TS (1988). Sites of action of opiates in production of analgesia. In: Fields HL \& Besson JM (Editors), Progress in Brain Research. Vol. 77. Elsevier, New York, 371-394.

20. File SE \& Rodgers RJ (1979). Partial anxiolytic action of morphine sulphate following microinjection into the central nucleus of the amygdala in rats. Pharmacology, Biochemistry and Behavior, 11: 313-318.

21. Rodgers RJ \& File SE (1979). Exploratory behavior and aversive thresholds following intra-amygdaloid application of opiates in rats. Pharmacology, Biochemistry and Behavior, 11: 505-511.

22. Zhou ZF, Xuan YT \& Han JS (1984). Analgesic effect of morphine injected into ha- 
benula, nucleus accumbens or amygdala of rabbits. Acta Pharmacologica Sinica, 5: 150-153

23. Davis $M$ (1986). The role of the amygdala in conditioned fear. In: Aggleton JP (Editor), The Amygdala: Neurobiological Aspects of Emotion, Memory, and Mental Dysfunction. Wiley-Liss, New York, 339351.

24. al-Rodhan N, Chipkin R \& Yaksh TL (1990). The antinociceptive effects of $\mathrm{SCH}$ 32615, a neutral endopeptidase (enkephalinase) inhibitor, microinjected into the periaqueductal, ventral medulla and amygdala. Brain Research, 520: 123-130.

25. Ma QP, Yin GF, Ai MK \& Han JS (1991). Serotonergic projections from the nucleus raphe dorsalis to the amygdala in the rat. Neuroscience Letters, 134: 21-24.

26. Plasnik A, Danysz $W$ \& Kostowski $W$ (1985). Some behavioral effects of microinjections of noradrenaline and serotonin into the amygdaloid body of the rat brain. Physiology and Behavior, 34: 481-487.

27. Lico MC, Hoffmann A \& Covian MR (1974). Influence of some limbic structures upon somatic and autonomic manifestations of pain. Physiology and Behavior, 12: 805-811.

28. Abbott FV \& Melzack R (1978). Analgesia produced by stimulation of limbic structures and its relation to epileptiform afterdischarges. Experimental Neurology, 62: 720-734.

29. Sha L, Huang P, Ding W \& Teng G (1993). The inhibitory effects of stimulating AC, $A L, B N S T$ and $A H L$ on visceral pain. Chen Tzu Yen Chiu Acupuncture Research, 18: 37-43.

30. Mena NB, Mathur R \& Nayar U (1995). Amygdalar involvement in pain. Indian Journal of Physiology and Pharmacology, 39: 339-346.

31. Zimmermann M (1983). Ethical guidelines for investigation of pain in conscious animals. Pain, 16: 109-110.

32. König JFR \& Klippel RA (1974). The Rat Brain, a Stereotaxic Atlas. Krieger, New York.

33. Litchfield JT \& Wilcoxon F (1949). A simplified method of evaluating dose-effect experiments. Journal of Pharmacology and Experimental Therapeutics, 96: 99113.

34. Azami J, Llewelyn MB \& Roberts MHT (1982). The contribution of nucleus reticularis paragigantocellularis and nucleus raphe magnus to the analgesia produced by systemically administered morphine, investigated with the microinjection technique. Pain, 12: 229-246.
35. Applegate CD, Kapp BS, Underwood MD \& McNalli CL (1983). Autonomic and somatomotor effects of amygdala central nucleus. Stimulation in awake rabbits. Physiology and Behavior, 31: 353-360.

36. Thorn BE, Applegate L \& Jones K (1990). The relative efficacy of monopolar vs. bipolar electrodes in stimulation-produced analgesia. Experimental Brain Research, 79: 266-270.

37. Frenk H \& Yitzhaky J (1981). Effects of amygdaloid binding on the pain threshold of the rat. Experimental Neurology, 71: 487-496.

38. Mayer DJ \& Hayes RL (1975). Stimulation-produced analgesia: development of tolerance and cross-tolerance to morphine. Science, 188: 941-943

39. Mansour A, Fox CA, Burke S, Meng F, Thompson RC, Akil H \& Watson SJ (1994). Mu, delta, and kappa opioid receptor expression in the rat CNS: an in situ hybridization study. Journal of Comparative Neurology, 350: 412-438.

40. Arvidsson U, Riedl M, Chakrabarti S, Lee JH, Nakano AH, Dado RJ, Loh HH, Law PY, Wessendorff W \& Elde R (1995). Distribution and targeting of a $\mu$-opioid receptor (MOR 1) in brain and spinal cord. Journal of Neuroscience, 15: 3328-3341.

41. Gray TS, Cassell MD \& Kiss JZ (1984). Distribution of pro-opiomelanocortin derived peptides and enkephalins in the rat central nuclei of the amygdala. Brain Research, 306: 354-358.

42. Roberts GW, Woodhams PL, Polak JM \& Crow TJ (1982). Distribution of neuropeptides in the limbic system of the rat: the amygdaloid complex. Neuroscience, 7: 99-131.

43. Cassell MD \& Gray TS (1989). Morphology of peptide-immunoreactive neurons in the rat central nucleus of the amygdala. Journal of Comparative Neurology, 281: 320-333.

44. Akil H, Mayer DJ \& Liebeskind JC (1976). Antagonism of stimulation-produced analgesia by naloxone, a narcotic antagonist. Science, 191: 961-962.

45. Carstens $E$, Fraunhoffer $M$ \& Zimmermann M (1981). Serotonergic mediation of descending inhibition from midbrain periaqueductal gray, but not reticular formation, of spinal nociceptive transmission in the cat. Pain, 10: 149-167.

46. Carstens $E$, Culhane ES \& Banisadr $R$ (1990). Partial involvement of monoamines and opiates in the inhibition of rat spinal nociceptive neurons evoked by stimulation in midbrain periaqueductal gray or lateral reticular formation. Brain
Research, 522: 7-13.

47. Fang F \& Proudfit HK (1996). Spinal cholinergic and monoamine receptors mediate the antinociceptive effect of morphine microinjected in the periaqueductal gray on the rat tail, but not the feet. Brain Research, 722: 95-108.

48. Guimarães APC \& Prado WA (1994). Antinociceptive effects of carbachol microinjected into different portions of the mesencephalic periaqueductal gray matter of the rat. Brain Research, 647: 220-230

49. Saxena PR (1995). Serotonin receptors: subtypes, functional responses and therapeutic relevance. Pharmacological Therapeutics, 66: 339-368.

50. Phillips WJ, Enyeart JJ \& Hinkle PM (1989). Pituitary thyrotropin-releasing hormone receptors: local anesthetic effects on binding and responses. Molecular Endocrinology, 3: 1345-1351.

51. Mayer DJ \& Liebeskind JC (1974). Pain reduction by focal electrical stimulation of the brain: an anatomical and behavioral analysis. Brain Research, 68: 73-93.

52. Mizuno N, Takahashi O, Satoda T \& Matsushima R (1985). Amygdalospinal projections in the macaque monkey. Neuroscience Letters, 53: 327-330.

53. Sandrew BB, Edwards DL, Poletti CE \& Foote WE (1986). Amygdalospinal projections in the cat. Brain Research, 373: 235239.

54. Beitz AJ (1982). The organization of afferent projections to the midbrain periaqueductal gray of the rat. Neuroscience, 7 : 133-159.

55. Eberhart JÁ, Morrell JI, Krieger MS \& Pfaff DW (1985). An autoradiographic study of projections ascending from the midbrain central gray, and from the region lateral to it, in the rat. Journal of Comparative Neurology, 241: 285-310.

56. Rizvi TA, Ennis M, Behbehani MM \& Shipley MT (1991). Connections between the central nucleus of the amygdala and the midbrain periaqueductal gray: topography and reciprocity. Journal of Comparative Neurology, 303: 121-131.

57. Li YQ, Takada M, Matsuzaki S, Shinonasa $Y$ \& Mizuno N (1993). Identification of periaqueductal gray and dorsal raphe nucleus projecting to both the trigeminal sensory complex and forebrain structures: a fluorescent retrograde double-labeling study in the rat. Brain Research, 623: 267277.

58. Shaikh MB, Schubert K \& Siegel A (1994) Basal amygdaloid facilitation of midbrain periaqueductal gray elicited defensive rage behavior in the cat is mediated 
through NMDA receptors. Brain Research, 635: 187-195.

59. Cameron AA, Khan IA, Westlund KN, Cliffer KD \& Willis WD (1995). The efferent projections of the periaqueductal gray in the rat: a Phaseolus vulgaris-leucoagglutinin study. I. Ascending projections. Journal of Comparative Neurology, 351: 568-584.

60. Hopkins DA \& Holstege G (1978). Amygdaloid projections to the mesencephalon, pons and medulla oblongata in the cat. Experimental Brain Research, 32: 529547.

61. Canteras NS, Simerly RB \& Swanson LW (1995). Organization of projections from the medial nucleus of the amygdala: a PHAL study in the rat. Journal of Comparative Neurology, 360: 213-245.

62. Krettek JE \& Price JL (1978). Amygdaloid projections to subcortical structures within the basal forebrain and brainstem in the rat and cat. Journal of Comparative Neurology, 178: 225-253.

63. Veening JG, Swanson LW \& Sawchenko PE (1984). The organization of projections from the central nucleus of the amygdala to brainstem sites involved in central autonomic regulation: a combined retrograde transport-immunohistochemical study. Brain Research, 303: 337-357.

64. Wallace DM, Magnuson DJ \& Gray TS
(1989). The amygdalo-brainstem pathway: selective innervation of dopaminergic, noradrenergic and adrenergic cells in the rat. Neuroscience Letters, 97: 252-258.

65. DeSalles AF, Katayama Y, Becher MP \& Hayes RL (1985). Pain suppression induced by electrical stimulation of the pontine parabrachial region. Journal of Neurosurgery, 62: 397-407.

66. Jones SL \& Gebhart GF (1986). Characterization of coeruleo-spinal inhibition of the nociceptive tail flick reflex in the rat: mediation by alpha ${ }_{2}$-adrenoceptors. Brain Research, 364: 315-330. 